Book review

(C) Journal of International Students

Volume 12, Issue 1 (2022), pp. 279-281

ISSN: 2162-3104 (Print), 2166-3750 (Online)

doi: $10.32674 /$ jis.v12i1.4555

ojed.org/jis

\title{
International Student Experience in Australia: Learning and Living in a Parallel Society
}

Catherine Gomes. New York: Routledge, 2022. pp. 142.

Paperback: AUD252.

ISBN: 978-0-367-65535-8

Reviewed by Yuqi Lin, University of Melbourne, Australia.

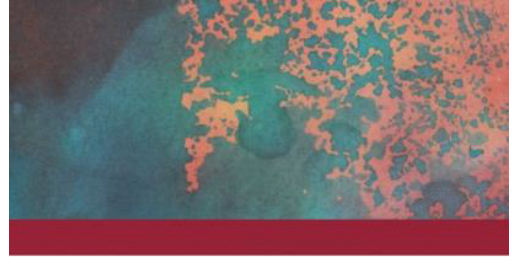

PARALLEL SOCIETIES OF INTERNATIONAL STUDENTS IN AUSTRALIA

CONNECTIONS, DISCONNECTIONS, AND A GLOBAL PANDEMIC

Catherine Gomes



More than 540,000 international students enrolled in Australian educational institutions and lived in Australia as temporary migrants in 2021 . While these students enjoy a high level of mobility, they face considerable academic and personal challenges, and their situations may have been adversely affected by the pandemic. Catherine Gomes' latest publication, entitled Parallel societies of international students in Australia: Connections, disconnections, and a global pandemic, explores international students' social and cultural spaces in their host country. Drawing on a decade of research, the author proposes the concept of parallel societies to describe the international student-only spaces which operate parallel to local societies. Taking Melbourne- the state capital of Victoria, Australia - as an example, she further investigates international students' support structures and social networks during the pandemic. 
This book enriches discussion of the international student experience by specifying the sociocultural space - parallel societies - that international students create in their host country. The introduction presents the alarming vulnerability of international students during the pandemic, which was countered by a sense of belonging and support engendered by parallel societies. To better understand this phenomenon, the introduction explores the developmental path of a parallel society and posits that alongside higher education internationalization, a new economy has emerged within the Australian market to provide services for international students, for example, international student accommodations and ethnic restaurants. As such, international students are provided with physical spaces to make connections and form networks. The author points out that membership is critical in parallel societies, as all members must be foreigners in Australia, international students in local educational institutions, and temporary visa holders. Consequently, multinational interaction is a predominant feature of international student parallel societies. In this multinational parallel society, international students can enhance their cultural understandings by interacting with each other while exploring the culture and societies of the host country together. Despite these benefits, the author finds that living in a parallel society may exclude international students from outside information.

Chapter 2 expands upon the argument that parallel societies could help international students develop a sense of belonging. This chapter identifies common meeting places for international students, including airport welcomes and orientation, campus, accommodation, and extra-curriculum activities. In these places, international students are able to connect with both existing and fresh members in parallel societies. It is highlighted that as student visa holders, international students are provided with a temporary identity allowing them to engage with the broader community. During their Australian experiences, international students share information, offer emotional support, and make social connections through their religious and online networks. In this way, they create a home away from home. The disconnections between international students and domestic learners are further discussed in Chapter 3. Specifically, the author highlights the us and them dichotomy that international students use to describe their relations with domestic students. Such an expression reflects that while international and domestic students shared a spatial environment, they had and have different experiences. The author points out some international students' perception of "Australians as white" and their understanding of multiculturalism. Regarding the latter aspect, the author finds that international students have little interest in learning about Australian policies, culture, and society. Meanwhile, the geographical distance between international students and their home-based friends makes it difficult to maintain friendships, leading to disconnections between parallel societies and home societies.

Acknowledging these disconnections, Chapter 4 further investigates the reasons behind the creation of international students' parallel societies. It studies international students' expectations; conceptions; and understanding of education programs, Australian societies, and Australians and outlines the misalignment between their Aussie dreaming and their lived realities. Meanwhile, this chapter 
stresses certain misperceptions of international students in the Australian public, including misconceptions like "backdoor migrants" and "cash cows." Nevertheless, international students have become a political hot button and, as such, have been utilized by politicians. Their existence is also becoming a heated topic in the media, where some Australians express their frustration and criticism toward international students. Considering these elements, the author argues that the creation of parallel societies is unavoidable and indeed have only become thornier in the pandemic. In Chapter 5, the author depicts a picture of a damaged international education industry and illustrates the vulnerability of international students. Specifically, she analyzes Australia's problematic responses to international students, namely travel suggestions (self-quarantine in a third country) and insufficient financial aid. These practices have pushed international students to depend on each other and look to their parallel societies for support. During Covid-19, fatal flaws in the existing international education system have been exposed. In this regard, the author advocates that researchers should consider applying conceptual lenses informed by critical theory. Moreover, Gomes asserts that it is vital to maintain an open attitude toward pandemic-related changes and redefine the concept of international students accordingly.

Parallel Societies of International Students in Australia Connections, Disconnections, and a Global Pandemic innovatively studies international students' geographical, cultural, and social spaces in their host country. The relevant scholarly literature has referred to international students' lived place as the third space, a grey area, describing liminality between host and home countries. However, little evidence has been produced about international students' social interactions or daily practices in the proposed, restricted space. In this regard, the book at hand effectively fills a gap by specifying the sociocultural space of international students in one particular host country and outlining the interactions between these spaces. While this book uses Melbourne as the context of the case studied, its implications regarding the conceptualization of international students' experience, re-formation of the international education system, and re-examination of core concepts, such as international students' mobility in internationalized and globalized higher education, are remarkable and well worth reading. Based on the insights provided in the book, an essential avenue to explore broader theoretical frames for future research on the international student experience would include the consideration of the intersectionality among various international student parallel societies in Australia and their host societies. Other factors affecting the ways these societies interact, such as the geographical and sociocultural differences within a society and between countries, and the nuances of individual experiences, would also need to be considered.

YUQI LIN is researching the sociology of education; her interests lie in higher education policy, globalization and the internationalization of higher education, and the well-being of international students. Email: yuqilin.alison@gmail.com 